\title{
Cognitive sequelae in relationship to early indices of severity of brain damage after severe blunt head injury
}

\author{
D N BROOKS, M E AUGHTON, M R BOND, P JONES AND S RIZVI
}

From the Departments of Psychological Medicine, Southern General Hospital, Glasgow, Withington Hospital, Manchester, and Ravenscraig Hospital, Greenock

SUMMARY A group of 89 severely head injured patients was tested psychologically within two years of injury, and test performance was related to indices of brain damage. Duration of coma (Glasgow Coma Scale) bore little relationship to later cognitive outcome but duration of posttraumatic amnesia significantly predicted cognitive performance. Patients with an operated haematoma performed better than non-operated cases, reflecting a selection bias. The side of haematoma was not significant, nor were the presence, or type, or side of skull fracture.

In studies of cognitive outcome after blunt head injury, the main question has been the contribution of severity of brain damage to the severity of cognitive dysfunction, and a range of indices of severity have been reported with varying results.

Ruesch ${ }^{1}$ found no difference in cognitive outcome between 17 cases described as "severe" (showing in total, three subdural haematomas, ten skull fractures, and ten cases with bloody CSF), and 53 cases with loss of consciousness only (the maximum duration of coma being 24 hours). However, duration of coma was important, not only in depressing intellectual level, but in leading to greater variability of cognitive performance within the longer coma patients. Ruesch also noted that the greater the neurological deficit, the greater the cognitive loss. Tooth $^{2}$ showed that patients with abnormal neurological signs were poorer cognitively than those not showing such signs, and the presence of signs was associated with increasing duration of coma and disorientation. Disorientation (assessed by post-traumatic amnesia) was an important predictor of cognitive outcome, unlike skull fracture. Despite significant associations between severity of injury and cognitive loss, Tooth noted "while group differences are clear enough, the deviation of individuals may be ... so variable that the method is of limited

Address for reprint requests: Dr DN Brooks, Department of Psycholog:cal Medicine, Southern General Hospital, Glasgow GS1 F4T.

Accepted 24 October 1979 value in the assessment of the individual case."

More recently, Kløve and Cleeland ${ }^{3}$ showed, like Tooth, ${ }^{2}$ that skull fracture was unimportant as a predictor of cognitive performance, and while patients showing focal or neurological signs appeared to perform at a lower level cognitively than those without, the association between signs and cognitive loss was "relatively minor". These authors also examined the influence of coma duration, defining coma as the time to become "responsive to verbal command." In this analysis they compared patients seen within four months of injury, and those within seven and 18 months. The results were ambiguous. Initially each of these two "time" groups were subdivided into four sub-groups in terms of coma, and these were then compared on cognitive tests by means of analysis of variance. This showed no significance association between coma and test score in the four month group, but performance on measures of memory and psychomotor function was inversely related to come duration in the "late" group. However, the correlation between coma and a composite cognitive impairment index was highly significant within the first three months after injury but not significant when patients tested later were examined.

Levin et $a l^{4}$ studied language following head injury, and showed a greater frequency of dysphasia in patients with any coma, than in those with none. Patients with coma longer than 24 hours showed significantly poorer performance on many language measures than those with shorter coma. 
Duration of post-traumatic amnesia (PTA) has been widely used as an index of severity of diffuse brain damage. ${ }^{5}$ Russell $^{6}$ showed that clinically assessed cognitive loss increased with increasing PTA, and Brooks ${ }^{7}$ and Brooks and Aughton $^{8}$ found a negative association between memory test scores and PTA in patients seen within two years of injury. Mandleberg ${ }^{9}$ studied PTA and intellectual loss on the Wechsler Adult Intelligence Scale $^{10}$ and found increasing PTA was associated with reduced performance IQ up to six months after injury, and reduced verbal IQ up to three months. Beyond six months after injury, PTA was not significantly associated with cognitive score, although Mandleberg did note that "a trend was apparent for the longer PTA groups to obtain slightly lower scores than the shorter PTA groups." In view of the range of results obtained with the range of severity measures, the current study aimed to examine a number of indices of severity in relation to cognitive outcome.

\section{Method}

PATIENT POPULATION

Eighty-nine patients (table 1) were selected from admissions to the Neurosurgical Unit of the Institute of Neurological Sciences, Glasgow. These patients were examined once only on a range of neuropsychological tests, and as table 1 shows, the patients were seen within two years after injury. This neurosurgical population contains many patients with operable lesions such as intracranial haematoma, and 59 patients were diagnosed as suffering a haematoma, and of these 52 underwent an operation for its removal.

\section{MEASURES OF SEVERITY OF BRAIN DAMAGE}

Measures were chosen to assess severity both of diffuse and focal damage as follows:

(a) Diffuse damage

(1) Coma Duration

62 patients had been assessed on the Glasgow Coma Scale ${ }^{1112}$ and the number of days to emerge from coma was therefore easily available on these patients. Coma was de-

Table 1 Head injured cases

\begin{tabular}{lllll}
\hline PTA (days) & 7 or less & $8-14$ & Over 14 & Unknown \\
\hline $\mathrm{N}$ & 23 & 14 & 38 & 14 \\
Time (months) & 6 or less & $7-12$ & $13-24$ & \\
$\mathrm{~N}$ & 66 & 16 & 7 & \\
Age (years) & $15-30$ & $31-45$ & $46-65$ & \\
$\mathrm{~N}$ & 33 & 25 & 31 & \\
\hline
\end{tabular}

fined as the absence of eye opening responses, comprehensable verbal responses, and the ability to move limbs to command.

(2) Post Traumatic Amnesia Duration

PTA (defined as the interval between the injury and regaining continuous day-to-day memory), was assessed retrospectively by careful questioning, and the patients were subdivided into the broad PTA categories shown in table 1. PTA is a clinical measure that is open to inaccuracy, but no attempt was made to make very precise discriminations, 14 cases were judged to have "unknown" PTA because the research psychologist was not completely confident about her assessment in those cases.

(b) Focal damage

\section{(1) Intracranial Haematoma}

The effects of haematoma were estimated by comparing patients with neurosurgically verified and removed haematomas with those who had no operation. Patients with left and right sided unilateral haematomas were then compared.

(2) Skull Fracture

Effects of fracture were estimated by subdividing patients with a fracture of any type, and those without, for an initial analysis. A further examination was made within the fracture group of the effects of type and laterality of fracture. This was done in order to replicate Smith's, ${ }^{13}$ and Roberts' ${ }^{14}$ report that the laterality of skull fracture predicted the pattern of cognitive deficit.

\section{(c) Other Measures}

\section{(1) Age}

The influence of age on outcome was examined by subdividing head injured patients into those above and those below the age of 30 years and comparing the two groups.

\section{PSYCHOLOGICAL TESTS}

\section{(1) Intelligence}

This was examined using the Raven's Progressive Matrices $^{15}$ which assess perceptual and conceptual aspects of problem solving. Verbal intellect was assessed by the Mill Hill Vocabulary Scale $^{61}$ which measure vocabulary level. Scores were expressed as deviation IQs. ${ }^{17}$

\section{(2) Learning and memory}

These were examined by two verbal and one nonverbal tests. The verbal tests were Logical Memory and Associate Learning. Logical Memory incorporated Story 1 of Form 1 of the Wechsler Memory Scale ${ }^{18}$ requiring the patient 
to recall a short story immediately after auditory presentation, and again 30 to $60 \mathrm{~min}$ later without warning. Associate Learning was assessed by the Inglis Paired Associate Learning test ${ }^{19}$ in which patients had to learn three unrelated pairs of words to a criterion of three consecutive errorless trials. Patients who failed to reach this criterion by ten trials stopped the test. The test was repeated (delayed learning) without warning after 30 to 60 minutes. Logical Memory score was the number of items (defined by Wechsler) recalled, and for Associate Learning, the number of errors. Nonverbal learning and memory was assessed by the Rey Picture ${ }^{20}$ in which the patient copied a complex asymmetrical geometric design, followed, without warning, by Immediate Recall, and Delayed Recall 30 to 60 min later.

\section{(3) Language}

Language was assessed simply by three measures of Word Fluency (WF1, 2 and 3), in which the patient had to produce in three 60 second trials, firstly, the names of as many animals as possible, followed by as many words as possible beginning with the letter "s", followed by words beginning with " $\mathrm{j}$ ". This is an extension of the method reported by Borkowski et al. ${ }^{21}$ Comrehension was measured by the 21 questions in Part 5 of the De-Renzi and Vignolo Token Test. ${ }^{22}$

(4) Perceptual and Constructional Skills

These were assessed by scoring the copy of the Rey Picture and by means of the Block Design subtest of the Wechsler Adult Intelligence Scale $^{10}$ in which patients constructed patterns of increasing complexity out of coloured blocks. The test battery was designed by one of the authors (DNB) together with Drs H van Dongen and $F$ van Harskamp of the Department of Neuropsychology, Erasmus University, Rotterdam, and Drs B Deelman and E van Zomeren of the Department of Neurology, Academisch Ziekenhuis, Groningen.

\section{Results}

\section{MEASURES OF DIFFUSE BRAIN DAMAGE Coma Duration}

The 62 head injured patients who had been monitored on the Glasgow Coma Scale were subdivided into 22 cases with a coma of one day or less, 26 with a coma of two to three days, and 13 with a coma of four days or more. The three sub-groups were compared on each cognitive test using one-way analysis of variance. On all cognitive measures, the $F$ ratios were insignificant, and there was no statistically significant influence of coma duration on later cognitive outcome. On most of the cognitive tests, the highest score was gained by the patients with a coma of one day or less, where the differences between the three sub-groups were usually small. Post traumatic amnesia duration (table 2)

The head injured group was subdivided into sub-groups of 23 patients with a PTA of seven days or less, 14 with a PTA of eight to 14 days, and 38 with PTA's of 15 days or more. For each cognitive test, the three sub-groups were compared by one-way analysis of variance. The exact number of patients tested on each measure is indicated in the $\mathbf{N}$ column of table 2 , which shows the six cognitive tests out of the fourteen used, in which increasing PTA was significantly associated with decreasing cognitive score. The tests which failed to reach significance in this respect were: Progressive Matrices, Mill Hill Vocabulary, Associate Learning Immediate, Word Fluency 1 and 2, Block Design, Rey Picture Copy, and Token Test. However, on each of these eight "insignificant" measures, the patients with the longest PTA performed at the lowest level, and on the Progressive Matrices, and Associate Learning Immediate, and Word Fluency 1 , the $F$ ratios only just failed to reach conventional significance with $p$ values of 0.09 , 0.08 , and 0.07 respectively. The significant $F$ ratios were investigated further by Scheffé tests, showing that on all six cognitive scores, the shortest PTA sub-group performed significantly better than the longest. The middle sub-group with a PTA of eight to 14 days did not differ significantly from either of the other two subgroups. On only three of the eight "insignificant" cognitive measures (Mill Hill, Word Fluency 3, and Rey Copy) did the expected consistent reduction in score from shortest to medium to longest PTA fail to appear.

Table 2 PTA and cognitive scores: significant effects

\begin{tabular}{|c|c|c|c|c|c|c|c|c|c|}
\hline \multirow[t]{3}{*}{ Test } & \multicolumn{7}{|c|}{$P T A$ (days) } & \multirow[t]{2}{*}{$F$} & \multirow[t]{2}{*}{$P$} \\
\hline & \multirow[t]{2}{*}{$\mathbf{N}$} & \multicolumn{2}{|c|}{$\begin{array}{l}\text { "Short" } \\
0-7\end{array}$} & \multicolumn{2}{|c|}{$\begin{array}{l}\text { "Medium" } \\
8-27\end{array}$} & \multicolumn{2}{|c|}{$\begin{array}{l}\text { "Long" } \\
28 \text { or more }\end{array}$} & & \\
\hline & & $\chi$ & $\boldsymbol{\sigma}$ & $\chi$ & $\sigma$ & $\chi$ & $\sigma$ & & \\
\hline $\begin{array}{l}\text { L Memory } \\
\text { (Immed) } \\
\text { L Memory }\end{array}$ & $y^{y 4}$ & $10 \cdot 5$ & $4 \cdot 1$ & $9 \cdot 5$ & $4 \cdot 4$ & $7 \cdot 1$ & $5 \cdot 0$ & $3 \cdot 81$ & .03 \\
\hline $\begin{array}{l}\text { (Delay) } \\
\text { A Learnin }\end{array}$ & 74 & $8 \cdot 4$ & $4 \cdot 7$ & $7 \cdot 1$ & $4 \cdot 6$ & $4 \cdot 9$ & 3.9 & $4 \cdot 30$ & .02 \\
\hline $\begin{array}{l}\text { (Delay) } \\
\text { Word }\end{array}$ & 69 & $3 \cdot 4$ & $6 \cdot 7$ & $5 \cdot 6$ & $8 \cdot 9$ & $12 \cdot 5$ & $12 \cdot 1$ & $5 \cdot 85$ & .005 \\
\hline $\begin{array}{l}\text { Fluency } \\
\text { Rey Pictur }\end{array}$ & re & $10 \cdot 1$ & $5 \cdot 1$ & $7 \cdot 6$ & $4 \cdot 4$ & $5 \cdot 8$ & $3 \cdot 7$ & $5 \cdot 32$ & $\cdot 01$ \\
\hline $\begin{array}{l}\text { (Immed) } \\
\text { Rey Pictur }\end{array}$ & re & $19 \cdot 1$ & $11 \cdot 8$ & $13 \cdot 0$ & $7 \cdot 0$ & $10 \cdot 4$ & $5 \cdot 7$ & $4 \cdot 38$ & .02 \\
\hline (Delay) & 45 & $16 \cdot 4$ & $12 \cdot 2$ & $12 \cdot 3$ & $6 \cdot 0$ & $8 \cdot 4$ & $5 \cdot 5$ & $3 \cdot 74$ & .03 \\
\hline
\end{tabular}


2 MEASURES OF FOCAL BRAIN DAMAGE. Intracranial haematoma

The 52 cases who had been operated on for removal of a haematoma of any type or location were compared with 24 cases who had no operative procedure carried out. On five tests (Progressive Matrices, Logical Memory Immediate and Delayed, Word Fluency 2 and 3) the cases who had been operated performed significantly better than non-operated cases. On the remaining psychological tests (with the exception of the three versions of the Rey) the operated cases were nonsignificantly better than nonoperated cases. It might be expected that cases with a haematoma would have a less severe diffuse injury than those without, and the comparison of the operated haematoma and non haematoma cases in terms of PTA showed that this was the case (operated haematoma -PTA $=16 \cdot 2$, non-operated haematoma $-\mathrm{PTA}=21.0$; $\mathrm{t}=1.98, \mathrm{p}=0.05$ ).

The operated cases were then subdivided into 29 patients with left-sided haematoma and 26 with right sided haematoma, with the bilateral cases being excluded from the analysis. These two sub-groups were then compared on psychological measures by means of " $t$ " tests, which proved insignificant on all fourteen tests. There was therefore no evidence of any consistent trends, and the side of haematoma was irrel. evant as a predictor of cognitive outcome.

\section{Skull fracture}

By means of " $t$ " tests, the 65 cases with a skull fracture (bilateral in nine cases only) were compared with the 24 cases in whom no fracture was recorded. The only significant difference between these two groups was on Immediate recall of the Rey Picture, where cases with no fracture performed at a significantly lower level. However, the Rey was not given to all patients, and cnly seven cases in this analysis appeared in the no-fracture group.

Within the fracture group an analysis was made of the influence of type and side of fracture. The mere presence of a fracture was not important, but this is not surprising as a fracture may be considered to indicate skull rather than brain damage. On a simple contre coup model cf head injury, site and side of fracture may be important, as had been hypothesised by Smith $^{\mathbf{1 3}}$ and Roberts, ${ }^{14}$ but this hypothesis is not stated with any conviction in view of the very strong evidence for a diffuse damage mechanism in blunt head injury. ${ }^{23}$ However, it was investigated by comparing the 32 left sided fracturc cases with the 23 right sided fracture (excluding bilateral cases), using " $t$ " tests. The only significant result was on the Progressive Matrices with left sided cases scoring significantly higher (left, 92.8; right, 84.6; $\mathrm{t}=2.33, \mathrm{p}=0.02$ ). On the remaining cognitive tests, left sided cases were either slightly better or indistinguishable from right sided cases, and side of fracture is not important in predicting outcome in this series, thereby failing to support Smith's and Roberts' contention that side of impact significantly predicts fattern of cognitive deficit in severe head injury.

Type of facture was investigated by comparing 51 cases with linear fracture only with eight cases with depressed fracture only. Again, " $t$ " tests were used, but the small number of cases makes interpretation difficult. The only significant " $t$ " test was on the Rey Picture Copy, where depressed fracture cases performed significantly worse.

There was, naturally, a considerable overlap between cases with a fracture and those with a haematcma, with 51 of the 65 fracture cases being operated on for haematoma.

\section{OTHER INDICES \\ Age}

The patients were divided into 33 cases aged 30 years or less and 56 cases aged above 30 years, and the two sub-groups compared using " $t$ " tests. The older cases were significantly worse on the Immediate and Delayed versions of the Rey, but on most of the other tests they were, if anything, better than the young cases. Age did not therefore seem to be an important variable in prediction cognitive outcome within the first two years after injury, although its association with longer term outcome remains to be investigated.

\section{Discussion}

The major portion of the study was devoted to two severity measures, PTA and coma, both of which related to early conscious level, and both of which assess primarily diffuse damage.

PTA showed a significant negative association with cognitive score in six of the fourteen tests, but even on the remaining eight "insignificant" tests, patients with a PTA of four weeks or more consistently performed at a lower level than those with a PTA of one week or less. Furthermore, in the eight "insignificant" tests, only three (Mill Hill, Rey Copy, and Word Fluency 3) failed to stow a consistent decrease in score 
from least to most severely injured cases. The cognitive measures showing the greatest association with PTA were, with only one exception, tests of learning and memory. The one exception (Word Fluency) requires the very rapid production of words by the patient, and this very time element may be significant.

The alternative index of diffuse damage was coma duration, and this did not have the predictive power of PTA, with none of the $F$ ratios reaching significance, although on most of the cognitive tests, patients with a coma of a day or less did show the highest score. Other studies have found an association between coma and cognitive outcome, but features of these studies make it difficult to compare their results with ours. Kløve and Cleeland ${ }^{3}$ used both analysis of variance, and correlation to examine the role of coma in predicting cognitive outcome. The correlation showed that coma predicted cognitive outcome within 12 months of injury but not later, whereas the analysis of variance showed an apparently opposite result. Levin et $a l^{4}$ examined coma in relation to post-traumatic aphasia, but many of their patients were tested while still in hospital (much sooner than our cases) and this early testing may explain their significant association between coma length and presence of dysphasia.

The measures of focal brain damage were almost entirely unsuccessful in predicting cognitive outcome. Skull fracture was unimportant, ferhaps partly because of the small numbers of cases in the sub-groups involved, but presumably primarily because skull fracture indicates kone rather than brain damage. Within the fracture group, laterality of fracture was quite unimportant in predicting cognitive level, unlike in the study reported by Smith ${ }^{13}$ and Roberts. ${ }^{14}$

The presence of an operated haematoma was important in this study. The 53 operated patients performed significantly better than those who were not operated on, and this reflects a difference in severity of diffuse damage between the two groups. Head injured patients admitted to a neurosurgical unit are selected on the basis of likely response to neurosurgical treatment, and these haematoma cases are likely to have suffered more focal than diffuse damage. The laterality of the haematoma did not prove to be an important variable for predicting cognitive level. The pattern of results that might have been expected on a focal damage model (left haematoma associated with a verbal learning defect) was not found almost certainly because the diffuse damage suffered by this kind of patient is an over-riding factor.

The age of the patient, selecting age as a cutoff, did not relate significantly to outcome on most of the tests used, but the range of ages chosen was purposely rather limited in this study, and it is possible that had more older patients been included, the result could have been different.

In conclusion, only PTA of the measures investigated showed a consistent relationship with cognitive deterioriation. Coma showed some slight clinical association, in that the shortest coma patients scored higher, but this was not statistically significant. Other indices, with the exception of the presence of an operated haematoma showed no association with cognitive outcome, and these findings testify to the extreme difficulty in predicting the likely cognitive outcome in an individual patient within two years after severe head injury.

\section{References}

1 Ruesch J. Intellectual impairment in head injuries. American Journal of Psychiatry 1944; 100:480-96.

2 Tooth G. On the use of mental tests for the measurement of disability after head injury. $J$ Neurol Neurosurg Psychiatry 1973; 10:1-11.

3 Kløve $\mathrm{H}$, Cleeland CS. The relationship of neuropsychological impairment to other indices of head injury. Scandinavian Journal of Rehabilitation Medicine 1972; 4:55-60.

4 Levin H, Grossman RG, Kelly PJ. Aphasic disorder in patients with closed head iniury. $J$ Neurol Neurosurg Psychiatry 1976; 39:1062-70.

5 Schachter DL, Crovitz HF. Memory function after closed head injury: a review of the quantitative research. Cortex 1977; 13:150-76.

6 Russell WR. The Traumatic Amnesias. New York: Oxford University Press, 1971.

7 Brooks DN. Wechsler Memory Scale performance and its relationship to brain damage after severe head injury. J Neurol Neurosurg Psychiatry 1976; 39:593-601.

8 Brooks DN, Aughton ME. Psychological consequences of blunt head injury. International Rehabilitation Medicine 1979; 1:160-5.

9 Mandleberg IA. Cognitive recovery after severe head injury. ${ }^{1} J$ Neurol Neurosurg Psychiatry 1976; 39:1001-7.

10 Wechsler D. Manual for the Wechsler Adult Intelligence Scale. New York: Psychological Corporation, 1955.

11 Teasdale G, Jennett B. Assessment of coma and impaired consciousness. Lancet 1974; July 13, $81-4$.

12 Jennett B. Assessment of the severity of head injury. J Neurol Neurosurg Psychiatry 1976; 39: $647-55$. 
13 Smith E. Influence of site of impact upon cognitive impairment persisting long after severe closed head injury. J Neurol Neurosurg Psychiatry 1974 ; 37:719-26.

14 Roberts AH. Severe Accidental Head Injury. London: Macmillan, 1979.

15 Raven JC. Guide to the Standard Progressive Matrices. London: HK Lewis, 1960.

16 Raven JC. Extended Guide to the Mill Hill Vocabulary Scale with the Progressive Matrices Scales. London: HK Lewis, 1962.

17 Peck D. The conversion of Progressive Matrices and Mill Hill Vocabulary raw scores into deviation I.Q's. J Clinical Psychology 1970; 26:67-70.

18 Wechsler D. A standardised memory scale for clinical use. $J$ of Psychology 1945; 19:870-95.
19 Inglis J. A Paired Associate Learning Test for use with elderly psychiatric patients. $J$ of Mental Science 1959; 105:440-3.

20 Rey A. L'examen psychologique dans les cas d'encephalopathie traumatique. Archives de Psychologie 1942; 28: No 112.

21 Borkowski JG, Benton AL, Spreen O. Word fluency and brain damage. Neuropsychologia 1967; 5:135-40.

22 De Renzi E, Vignolo LA. The Token Test: a sensitive test to detect receptive disturbances in aphasia. Brain 1962; 85:665-78.

23 Ommaya AK, Gennarelli TA. Cerebral concussion and traumatic unconsciousness. Brain 1974; 97:633-54. 